\title{
Bayesian Network based Elucidatory Model of Change for Flexible Academic System in Post- Graduate Classes
}

\author{
Humera Bashir \\ Department of Computer \\ Science, University of Karachi.
}

\author{
Tahseen Ahmed Jilani \\ Department of Computer \\ Science, University of Karachi.
}

\author{
Muhammad Azam \\ Shaheed Zulfikar Ali Bhutto \\ Institute of Science and \\ Technology, Karachi
}

\begin{abstract}
The purpose of this study is to apply Bayesian Network on change model that supports increase in number of graduate students in post-graduate classes. Change is the process of shifting from current position to desired position. Change can be brought from two modes i.e. behavioral and structural. Three main constraints that confront decision making by a graduate for getting enrolled in post-graduate studies include (i) Non-Readiness, (ii) Rigidity of Academic System and (iii) Shortage of Resources. Nonetheless, three core variables that counter constraints include (i) Readiness that is parenting Awareness Program and Student Counseling (ii) Flexible Academic System that is parenting Distance Learning Program and Flexible Schedule of Classes and (iii) Provision of Resources that is parenting Scholarship Program and Higher-Education Allowance for Parents. A survey feedback of 121 respondent (graduate and not studying further) from Karachi represents that "Flexible Academic System" is more likely to be considered while making decision for getting admission in post-grad studies. Cumulative causal effect of "Flexible Academic System" to the dependent variable "Admissions in Post-Grad Programs" is 0.4, "Readiness" has 0.19 and "Provision of Resources" has 0.18. Cumulative causal effect of entire model is 0.77 that seems fruitful, if executes. In this context, government and NGOs should work on Readiness and Provision of Resources while universities should offer Flexible Academic System in order to increase number of students in post-grad classes.
\end{abstract}

\section{General Terms}

Bayesian Analysis, Change Management, Machine Learning, Organizational Behavioral.

\section{Keywords}

Bayesian Network, Post-Grad Studies, Causal Relations.

\section{INTRODUCTION}

Bayesian Network is directed/vectored acyclic graph of different random variables and their interdependencies based on probability. Variables can be continuous or discrete in nature [1]. Dependency relation of one variable to other variable(s) can be backed by any or combination of experimental, observational or trend-based data. Bayesian Network is directional and conditional structure of interdependent variables, where one or more variables parenting one or more child variables and establishes causal relationship between/among them [6].

Bayesian Analysis is a formulated statistical method to estimate parameters of a distribution based on observations [7]. In Bayesian Networks, there are two types of variables i.e. parent or child where child variable is dependent on parent variable. The relation of child and parent variable is directional at some probabilistic degree [2] [3]. Therefore, each Bayesian Network has four properties i.e. variables, dependency, directional relation, degree of probability between two or more variables [4].

Bayesian Network is rooted from Bayesian Theorem that advocates the conditional probability. The probability of an event before and after occurrence of situational variables differs [8] [9]. For instance, occurrence probability of variable " $A$ " as independent variable will be different if the same variable "A" depends on other variable " $B$ ". Here, variable " $B$ " is called the evident event for the variable " $A$ ". The probability distribution for occurrence of variable " $A$ " without or before evident event i.e. variable " $\mathrm{B}$ " is called prior probability distribution. The probability distribution of variable " $A$ " will be different with or after the variable " $B$ " is taken into account. The formula of conditional probability is as under [11] [12]:-.

$$
\mathrm{P}(\mathrm{A} \mid \mathrm{B})=\frac{\mathrm{P}(\mathrm{B} \mid \mathrm{A}) \cdot \mathrm{P}(\mathrm{A})}{\mathrm{P}(\mathrm{B})}
$$

Whereas, the general form of Bayesian Belief Network is as under:-

$$
P\left(A_{1}, A_{2} \ldots . A_{N}\right)=\prod_{i} P\left(A_{i} \mid \text { parents }\left(A_{i}\right)\right)
$$

The term "change" is referred to the shift from current position to the desired position [5]. The change can be behavioral or structural in nature. Behavioral change is characterized as the modification of individual's or group's behavior into desired shape of behavior, for instance, the change in individuals' mindset for a certain habit like quit smoking, avoid speeding on the way etcetera is categorized as behavioral change [10][13]. On the other side, structural change is typified as modification into the system, process, procedure or spatial setting, for example, change in seating arrangement in class, policy of admission, academic process etcetera.

Statistics Department of Pakistan claims that only $28 \%$ of graduate students prefer to move ahead for higher (postgraduate) studies. This is dilemma for a developing nation because chunk of students prefer professional career instead of philosophic/post-grade studies. This seems a normal issue in short-run but in long-run it is very critical because it leads to the dead end for innovative inventions and creation of research based knowledge. This paper is aimed to design an action-able framework for the government bodies, nongovernment organizations (NGOs) and universities to increase number of students in post-grad classes.

\section{HIERARCHAL STRUCTURE OF CONFRONTING VARIABLES}

There are three main variables that confront students to move ahead for post-grad studies i.e. Non-Readiness (NRd), Rigidity of the Academic System (RgAS) and Shortage of Resources (SR); discuss in figure - 1:- 


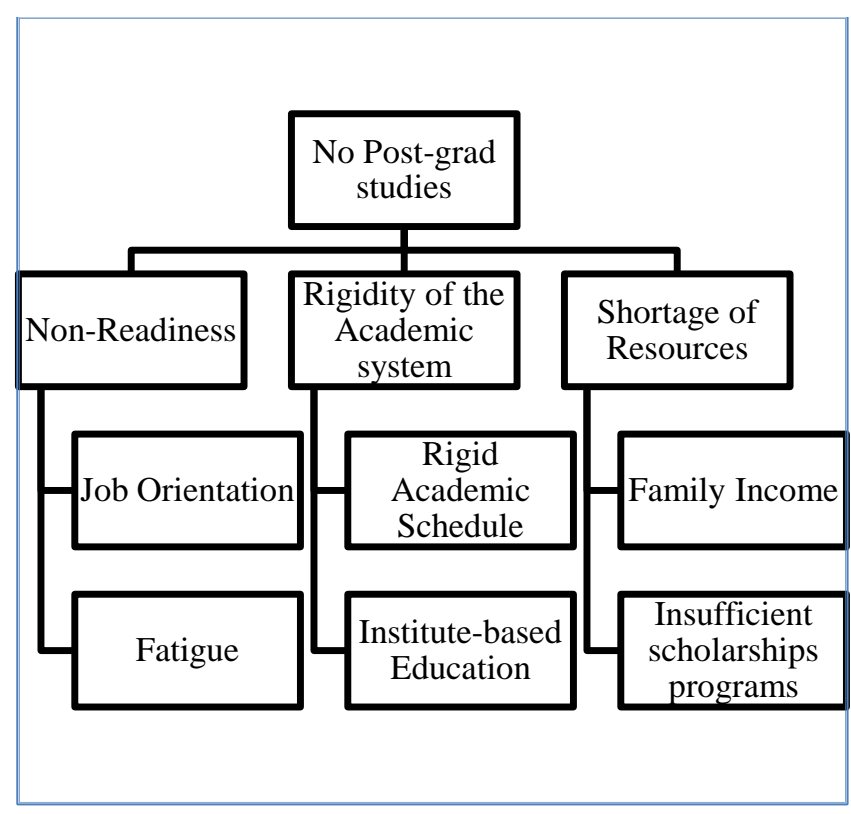

Figure 1: Hierarchal Structure of Confronting Variables

NRd is further caused by two main factors i.e. Job orientation and fatigue. The term Job orientation is referred to the preference of graduate students to earn money immediate after graduation rather than moving ahead for post-graduate studies. This factor is stronger in weak economies, mostly third world or developing countries like Pakistan. In such countries, job availability and earning structure is unbalanced due to which people seek for job in early stage before completion of post-graduate studies. They try for handsome earning during their professional life on the basis of on-job experience rather than academic excellence in their field. Second important factor for NRd is Fatigue. The term Fatigue refers to the tiredness from continuous conventional studies from childhood to early twenties that make students feel fatigues job; therefore, they try to skip from further studies.

RgAS is bifurcated into Rigid Academic Schedule and Institute based Education. The first factor passes on the least flexible academic system that makes students of post-grad level unavailable to move ahead. As stated earlier, most of the graduate students enter profession to earn money and on-job experience; therefore, they need highly flexible academic system so that they can accommodate further education parallel to their job/business. Institute based education rather than open or distance learning fashion is also one barrier among others. If graduate working youngsters are offered with open/distance learning programs they can easily manage their post-grad studies at remote areas without attending sessions at university.

Third major variable is SR that is bifurcated into Family Income and Insufficient Scholarship Programs. In Pakistan, monthly family income of $20 \%$ of the population is less than PKR 12,000/- while the half of the total population is earning (family income) less than PKR 17000/- per month that is very alarming situation in such high inflationary economy. That is why; most of the students do not prefer to go ahead for postgrad studies rather they try to start earning. Secondly, scholarship by public and private sector organizations is almost negligible in comparison with students graduating every year.

\section{BAYESIAN NETWORK - ELUCIDATORY MODEL OF CHANGE}

As discussed, NRd, RgAS and SR are three major constraints confronting students for not attending universities for post-grad studies. This paper establishes a Bayesian network based model for increasing number of students attending universities for post-grad studies. The said model contains variables countering aforesaid barriers in order to organize. There are three core variable parenting several child variables creating tendency among graduate students to send them universities for higher education. These variables are Readiness (Rd), Flexible Academics System (FAS) and Provision of Resources (PR).

First core variable, Rd, is parent variable of two i.e. Student Counseling (SC) and Awareness Program (AP) whereas AP further parenting two variables i.e. Media Campaign (MC) and Peer Pressure (PP). Second core variable, FAS, is parent of two variables Flexible Schedule (FS) and Distance Learning Programs (DLP). The third core variable, PR, is parent of two variables i.e. Scholarship (Sch) and Higher Education Allowance for Parents (HEAP). The Bayesian Network of said structure is shown in figure - 2:-

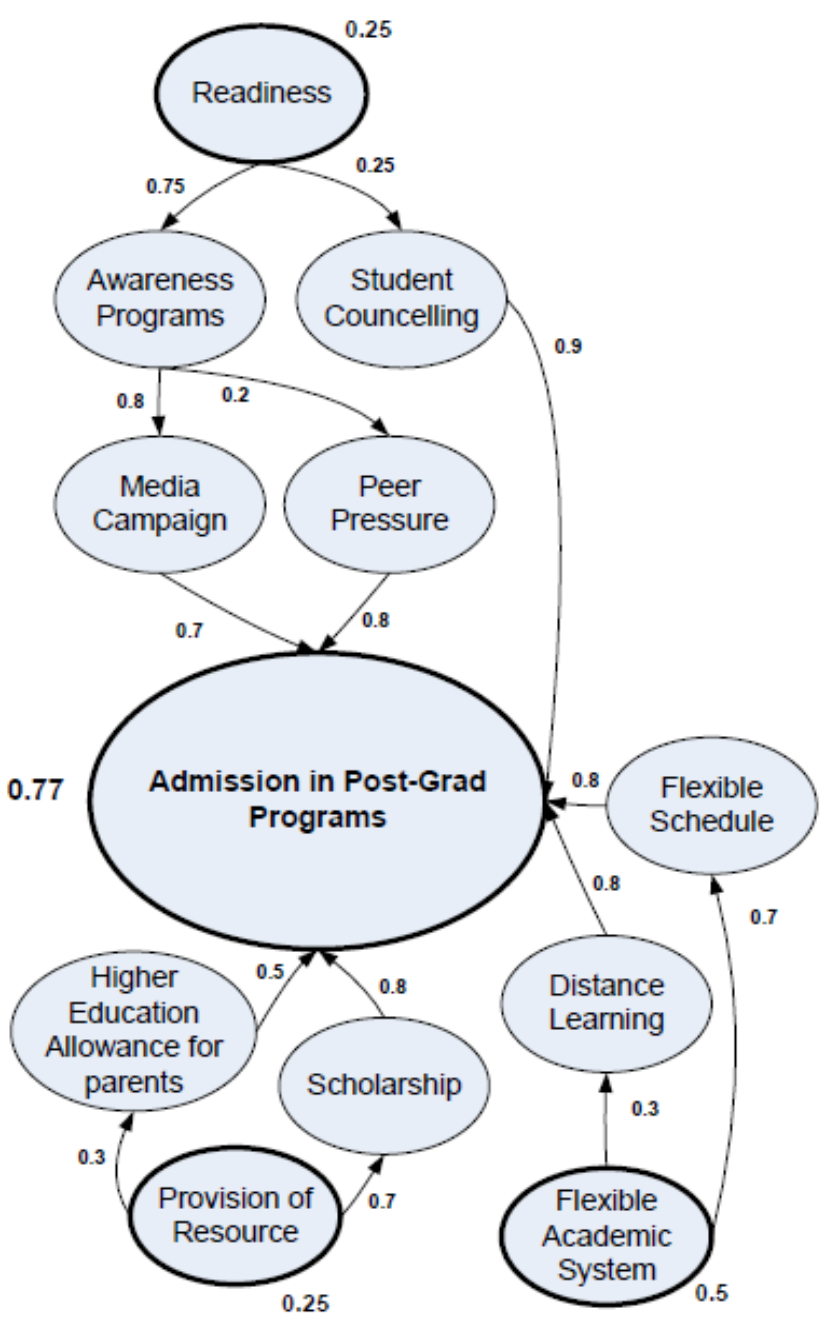

Figure 2: Bayesian Network - Elucidatory Model of Change

A survey, comprising feedback of 121 respondents who are doing job or running own enterprise after completion of graduation, suggests that RAS is more likely to happen than 
$\mathrm{Rd}$ and PR. A semi-open questionnaire was designed to get views of those graduate youngsters who were not intended to move ahead for higher studies due to any reason. Collected data was sorted, sifted and clustered in order to design the Elucidatory Model of Change shown in figure -2 .

There are total 7 causal relationships of core variables with dependent variable i.e. APGP. Such causal relationships along with their probabilistic proportion into dependent variable are depicted in table - 1:-

\begin{tabular}{|c|c|}
\hline Sr. & $\begin{array}{l}\text { Causal Relationship \& } \\
\text { Probabilistic Proportion }\end{array}$ \\
\hline 1 & $\begin{array}{l}\mathrm{Rd} \rightarrow \mathrm{AP} \rightarrow \mathrm{MC} \rightarrow \mathrm{APGP} \\
0.25 \times 0.75 \times 0.8 \times 0.7=0.105\end{array}$ \\
\hline 2 & $\begin{array}{l}\mathrm{Rd} \rightarrow \mathrm{AP} \rightarrow \mathrm{PP} \rightarrow \mathrm{APGP} \\
0.25 \times 0.75 \times 0.2 \times 0.8=0.03\end{array}$ \\
\hline 3 & $\begin{array}{l}\mathrm{Rd} \rightarrow \mathrm{SC} \rightarrow \mathrm{APGP} \\
0.25 \times 0.25 \times 0.9=0.0562\end{array}$ \\
\hline 4 & $\begin{array}{l}\mathrm{FAS} \rightarrow \mathrm{DLP} \rightarrow \text { APGP } \\
0.5 \times 0.3 \times 0.8=0.12\end{array}$ \\
\hline 5 & $\begin{array}{l}\mathrm{FAS} \rightarrow \mathrm{FS} \rightarrow \mathrm{APGP} \\
0.5 \times 0.7 \times 0.8=0.28\end{array}$ \\
\hline 6 & $\begin{array}{l}\mathrm{PR} \rightarrow \mathrm{HEAP} \rightarrow \mathrm{APGP} \\
0.25 \times 0.3 \times 0.5=0.0375\end{array}$ \\
\hline 7 & $\begin{array}{l}\mathrm{PR} \rightarrow \mathrm{Sch} \rightarrow \mathrm{APGP} \\
0.25 \times 0.7 \times 0.8=0.14\end{array}$ \\
\hline
\end{tabular}

The cumulative causal proportion of first core variable Rd comprising serial 1 to 3 is 0.19 ; second core variable FAS comprising serial 4 and 5 is 0.4 ; and third core variable PR comprising serial 6 and 7 is 0.18 . Therefore, FAS has greater causal effect on under discussion Elucidatory Model of Change. This significantly higher effect is due to some ground facts; discussed subsequently.

First ground reality is that the person who is not willing to go for post-grad studies is very difficult to change his/her decision. Because, there are many other domestic and social factors that intervene while making mind or getting ready for post-grad studies; for example, social barrier for girls to send them universities, tendency towards job and earning immediate after graduation, parents' preference to wed their children after graduation etcetera. Due to such social barriers, making students ready for post-grad studies is bit difficult task and not too effective tool; nonetheless, the causal effect of Rd $(p=0.19)$ is comparatively lower than $\operatorname{FAS}(p=0.4)$.

Second ground fact is that Higher Education Commission (HEC), universities and other bodies are offering merit and need based scholarships to scholars for post-grad studies. Numbers of students are already beneficiaries of such offerings/programs. Secondly, the semester fee for post-grad programs, especially in Public universities, is affordable. Most of students enrolled in post-grad programs are doing jobs or earning from their own enterprises. Due to this, the causal effect of PR $(p=0.18)$ is considerably less than FAS $(p=0.4)$ and almost equals to $\operatorname{Rd}(p=0.19)$.

Third ground fact is that, as discussed earlier, most of graduates start job or their own enterprise; out of them, one set of students cannot attend classes at day time, therefore, they want flexible schedule of classes in evening or weekend. Other set of students cannot attend 3 hours class even in evening or weekend; hence, they need distance learning programs. If universities are offering distance learning programs or flexible class schedules in evening or weekend; number of students in post-grad study programs can be increased.

The cumulative causal effect of Elucidatory Model of Change ( $p=0.77$ ) comprising $\mathrm{Rd}$, FAS and PR leads to the understanding that said model is fruitful and workable. Governing bodies at federal, provincial or university level, if executes campaign using said model, can bring ample number of students into post-grad classes.

\section{CONCLUSION}

The Elucidatory Model of Change consists of three core variables Rd, FAS and PR and multiple child variables based on Bayesian Network represents course of action to increase number of students in post-grad classes using structural and behavioral change. Nonetheless, the said model is blend of theories of Change Management and Bayesian Analysis. The said model consists of 7 causal relationships in total; where first core variable, Rd, affects dependent variable APGP through 3 causal relations; second and third core variables, FAS and PR, each affect APGP through 2 causal relationships. Cumulative effect of all 3 core variables and 7 causal relations on dependent variable APGP is $0.77(p=$ 0.77). Conclusively, it is recommended that government bodies and NGOs should focus on Rd and PR side. Work on Rd will bring behavioral change among graduates and PR will cause structural change in resource-provision programs by the government and NGOs. Parallel to this, universities should work on FAS enthusiastically to bring change in internalstructure of academic programs in order to make it flexible for graduates.

\section{REFERENCES}

[1] Andersen, S. K., Olesen, K. G., Jensen, F. V., and Jensen, F. (1989). HUGIN-A shell for building Bayesian belief universes for expert systems. In IJCAI89, Vol. 2, pp. 1080-1085.

[2] Baum, E. and Smith, W. D. (1997). A Bayesian approach to relevance in game playing. AIJ, 97(1-2), 195-242.

[3] Berger, J. O. (1985). Statistical Decision Theory and Bayesian Analysis. Springer Verlag.

[4] Bernardo, J. M. and Smith, A. F. M. (1994). Bayesian Theory. Wiley.

[5] Burnes, B. (2004). Managing Change (4th edn), Harlow: Pearson Education

[6] Charniak, E. and Goldman, R. (1992). A Bayesian model of plan recognition. AIJ, 64 (1), 53-79.

[7] Chater, N. and Oaksford, M. (Eds.). (2008). The probabilistic mind: Prospects for Bayesian cognitive science. Oxford University Press.

[8] Cooper, G. (1990). The computational complexity of probabilistic inference using Bayesian belief networks. AIJ, 42, 393-405. 
[9] Dagum, P. and Luby, M. (1993). Approximating probabilistic inference in Bayesian belief networks is NP-hard. AIJ, 60 (1), 141-153.

[10] Hayes, J. (2002). The Theory and Practice of Change Management, Chippenham: Palgrave.

[11] Jensen, F. V. (2007). Bayesian Networks and Decision Graphs. Springer-Verlag.
[12] Korb, K. B. and Nicholson, A. (2003). Bayesian Artificial Intelligence. Chapman and Hall.

[13] Paton, R. A. and Mc Calman, J. (2000) Change Management: A Guide to Effective Implementation (2nd ed), London: Sage. 